\title{
artigo
}

Macedo Silva, M.C.T:

Estratégias educacionais no ensino técnico em enfermagem durante a pandemia por coVID-19

\section{Estratégias educacionais no ensino técnico em enfermagem durante a pandemia por COVID-19}

\author{
Educational strategies in technical nursing education during the COVID-19 pandemic \\ Estrategias educativas em la educación técnica em enfermería durante la pandemia COVID-19
}

\begin{abstract}
RESUMO
Durante a pandemia, a obrigatoriedade do distanciamento social, mostrou uma nova forma de ensinar e de se reinventar. Objetivo: Apresentar estratégias de ensino utilizadas por um enfermeiro docente, durante o retorno às aulas presenciais no período de pandemia. Métodos: Trata-se de um relato de experiência profissional e pesquisa bibliográfica, a aplicabilidade dos métodos foi desenvolvido em uma Instituição de Ensino Técnico em Enfermagem, no mês de setembro de 2020. Resultados: As atividades realizadas que mais motivaram os discentes foram: storytelling, quiz e passa ou repassa. Quando o professor utiliza ferramentas voltadas para a teoria da andragogia, passa a observar o aluno como sujeito ativo no processo de aprendizagem. Conclusões: 0 trabalho deve ser coletivo, para se inserir uma pedagogia crítica, com um aprendizado dinâmico, fazendo com que o aluno em sua realidade, possa não causar danos em sua assistência prestada ao paciente.
\end{abstract}

DESCRITORES: Ensino; Pandemia; Educação em Enfermagem.

\section{ABSTRACT}

During the pandemic, the obligation of social distance showed a new way of teaching and reinventing itself. Objective: To present teaching strategies used by a teaching nurse, during the return to the classroom during the pandemic period. Methods: This is a report of professional experience and bibliographical research, the applicability of the methods was developed in an Institution of Technical Teaching in Nursing, in September 2020. Results: The activities that most motivated the students were: storytelling, quiz and pass or review. When the teacher uses tools focused on andragogy theory, he starts to observe the student as an active subject in the learning process. Conclusions: The work must be collective, to insert a critical pedagogy, with a dynamic learning, so that the student in his reality, may not cause damage in his assistance to the patient.

DESCRIPTORS: Teaching, Pandemic, Nursing Education.

\section{RESUMEN}

Durante la pandemia, la obligación de la distancia social mostró una nueva forma de enseñar y reinventarse. Objetivo: Presentar las estrategias de enseñanza utilizadas por una enfermera docente durante el regreso a las aulas en el periodo de la pandemia. Métodos: Se trata de un informe de experiencia profesional e investigación bibliográfica, la aplicabilidad de los métodos se desarrolló en una Institución de Educación Técnica en Enfermería, en septiembre de 2020. Resultados: Las actividades que más motivaron a los alumnos fueron: la narración de cuentos, el concurso y el pase o repaso. Cuando el profesor utiliza herramientas centradas en la teoría de la andragogía, empieza a observar al alumno como sujeto activo en el proceso de aprendizaje. Conclusiones: El trabajo debe ser colectivo, para insertar una pedagogía crítica, con un aprendizaje dinámico, para que el estudiante en su realidad, no pueda causar daño en su atención al paciente.

DESCRIPTORES: Educación, Pandemia, Enseñanza de la enfermería

RECEBIDO EM: 27/01/2021 APROVADO EM: 08/02/2021

\section{Maria Claudia Teixeira de Macedo Silva}

Enfermeira Docente na instituição Cefacs EEP HCFMUSP. Discente no Programa de Pós Graduação Mestrado Acadêmico em Educação - UNICID. Bacharel em Enfermagem. Especialista em Saúde Mental e Psiquiátrica, Especialista em Docência no Ensino Médio, Técnico e Superior na área da Saúde, Especialista em Enfermagem do Trabalho, Especialista em Educação Continuada e Permanente em Saúde.

ORCID: 0000-0002-3359-3557 


\section{INTRODUÇÃO}

E $m$ virtude, do aumento exponencial do COVID-19, por meio de transmissão generalizada, a Organização Mundial da Saúde (OMS) tratou o caso como pandemia. ${ }^{(1)}$ A fim de, controlar a propagação do vírus, o Brasil, adotou medidas preventivas de isolamento social, onde de um momento para o outro nos encontramos trancados dentro de casa, mudando os hábitos, conversas sendo realizadas pela pequena tela de um computador ou celular, famílias se encontrando a distância por videochamada quando sua realidade permitia, sem o abraço e o aperto de mão, escolas cancelando as aulas presenciais e partindo para uma estrutura remota. ${ }^{(1,2)}$

Como consequência, a repentina pausa nas atividades presenciais das escolas, seja no ensino técnico ou nível superior, que se associam-se com atividades teóricas e práticas, causam impactos no processo de aprendizagem a curto, médio e longo prazo. ${ }^{(2)}$ Notadamente, os mais afetados, são os sujeitos que vivem à margem da sociedade, sem auxílio de infraestrutura, com déficit socioeconômico, aquele que reflete a situação de desigualdade social, diante do ingresso aos serviços essenciais, dentre esses a educação. ${ }^{(2)}$

Todavia, os cursos de enfermagem, possuem carga horária que incluem aulas teóricas, teórico-práticas (realizadas em laboratório de enfermagem) e estágio supervisionado.

Durante a pandemia, a obrigatoriedade do distanciamento social, mostrou uma nova forma de ensinar e de se reinventar. Em contrapartida o docente, teve que encarar que o avanço tecnológico de um futuro próximo, chegou repentinamente e se instalou. Certamente, que algumas instituições de ensino em enfermagem, contam com todo aparato tecnológico em suas aulas, mas uma grande maioria não.

O processo de aprendizagem intitulada como Andragogia, criada por Malcolm Knowles, conceitua o aluno como um indivíduo maduro, onde o professor é o facilitador do conhecimento indicando o
Além disso, uma

das ferramentas da

andragogia que vem

se destacando são

as metodologias

ativas. Mas para

falar sobre esses

métodos, devemos

primeiro saber 0

que caracteriza essas

metodologias, e no

que elas diferem das

metodologias que

usamos até agora.

Para se preparar uma

aula é necessário

planejamento com

objetivos claros e que

devem ser escritos a

partir do ponto de

vista do aluno. caminho e sensibilizando esse indivíduo para uma aprendizagem com elementos mediadores. ${ }^{(3)}$

Partindo dessa premissa, podemos refletir sobre o capital biográfico de um sujeito, onde a experiência se adquire ao longo da vida, onde recorremos como busca de referência para refletir, agir ou reagir, por meio de uma constituição humana e histórica. ${ }^{(4)}$

A andragogia se apoia em quatro pilares, sobre as características do indivíduo aprendiz, na vida adulta: Deixa de ser dependente para ser independente, com a necessidade de se autodirigir; Acumula reservas de experiências com um maior volume de recursos de aprendizagem; A motivação no processo de aprendizagem está voltada para buscar e desenvolver os papeis sociais; A perspectiva em relação a aplicabilidade dos conhecimentos é modificada, pois sua aprendizagem deixa de ser centralizada no conteúdo, para ser centralizada no problema. ${ }^{(3)}$

Sob o mesmo ponto de vista, pode-se afirmar que o sujeito epistêmico e o sujeito biográfico permanecem amalgamados. Existindo uma dicotomia entre ambos, possibilitando religar conhecimento e autoconhecimento por meio das narrativas da experiência. ${ }^{(4)}$

Além disso, uma das ferramentas da andragogia que vem se destacando são as metodologias ativas. Mas para falar sobre esses métodos, devemos primeiro saber o que caracteriza essas metodologias, e no que elas diferem das metodologias que usamos até agora. Para se preparar uma aula é necessário planejamento com objetivos claros e que devem ser escritos a partir do ponto de vista do aluno. ${ }^{(5)}$

Adotar como ferramentas de aprendizagem os métodos ativos, nos cursos na área da saúde, auxiliam os alunos a serem proativos, principalmente pelo fato de se envolverem em atividades complexas e que necessitam tomada de decisão e avaliação dos resultados. As instituições de ensino profissional devem preparar seus discentes para os exercícios das funções mentais, cognitivas e sócio-afetivas, para que possam aprender com autonomia e assimilar 
o alto número de informações. ${ }^{(6)}$ Porém é necessário que os docentes também estejam engajados no desenvolvimento das competências profissionais durante o preparo dos estudantes para sua formação critico social. ${ }^{(7)}$

As metodologias ativas são práticas pedagógicas, que colocam os alunos a serem os principais agentes do aprendizado, e o professor como o mediador de conteúdo, onde detém competências técnicas e comportamentais, associadas a habilidades de colaboração e flexibilidade na transmissão do conhecimento, estimulando a autonomia na aprendizagem do aluno. ${ }^{(5,8,9,10)}$

O desafio na implantação dos métodos ativos na formação, acontece quando ainda se acredita que o professor deve ser o centro do processo de ensino e a sala de aula é o único local em que a aprendizagem pode acontecer. Esse desafio faz com que o educador mude sua forma de pensar e que a educação ultrapasse as paredes da sala de aula, fazendo com que os alunos e o docente tenham uma proximidade, para desenvolver suas habilidades e seus conhecimentos através das atitudes críticas-reflexivas em uma aprendizagem com cenários reais. ${ }^{(11,12)}$

Como perguntas norteadoras ressalto: É possível em um curto período de tempo, auxiliar os discentes com pouca infraestrutura tecnológica, seja por parte da escola, ou seja, por parte socioeconômica do aluno? Como manter o aluno motivado e engajado durante o processo de ensino aprendizagem com novas tecnologias? É possível fazer com que o professor modifique sua forma de lecionar usando meios tecnológicos ou improvisando sem infringir as técnicas e a teoria apresentadas?

Assim, o presente artigo tem como objetivo apresentar por meio de um relato de experiência, as estratégias de ensino utilizadas por um enfermeiro docente, durante o retorno às aulas presenciais no período de pandemia.

\section{MÉTOdO}

Trata-se de um relato de experiência profissional e pesquisa bibliográfica a par- tir de referências publicadas no período de 2008 a 2020, em língua portuguesa e inglesa, inicialmente no banco de dados Scielo (Scientific Electronic Library Online), com o uso dos descritores: Ensino, Pandemia, Educação em Enfermagem.

Esse estudo foi desenvolvido em uma Instituição de Ensino Técnico em Enfermagem, que faz parte de um complexo hospitalar de grande porte, situado na cidade de São Paulo.

Para a escolha do perfil dos participantes, optou-se por trabalhar com 38 alunos, do curso Técnico em Enfermagem, com faixa etária entre 18 à 39 anos. Como critério de inclusão, ter cursado a disciplina de fundamentos do cuidado fase I e II, ter realizado os estágios supervisionados, correspondentes a essa disciplina.

De acordo com o método utilizado, fica dispensado a aprovação do Comitê de Ética em Pesquisa conforme a resolução CNS no 510/2016. Alinhado com a instituição de ensino participante, o estudante com comorbidade pertencente ao grupo de risco para COVID-19, foi orientado a permanecer em ensino remoto, acompanhando a aula de forma online, por plataforma própria institucional.

Após a realização de uma avaliação diagnostica, que teve como objetivo validar os conteúdos ministrados no período do ensino online, onde os resultados não foram satisfatórios, iniciou-se a coleta de dados e aplicabilidade dos métodos que aconteceram no mês de setembro de 2020, período do retorno das aulas presenciais, por meio de 11 encontros com carga horaria de 5 horas/aula. Os participantes foram divididos em três grupos e em salas separadas, respeitando o limite de alunos preconizado pelas autoridades devido a pandemia, rodiziando entre as aulas teóricas e aula teórico - prático.

$\mathrm{O}$ instrumento utilizado, foi definido de acordo com os recursos disponíveis na instituição, respeitando a singularidade de cada um. Optou-se por aplicar um mapa mental, de modo que professor, aluno e colega, pudessem se conhecer melhor e assim incluir outras estratégias de ensino como a gameficação. A princípio as per- guntas que circundavam o mapa mental, serviram para direcionar a roda de conversa, favorecendo narrativas por meio das histórias de vida e nesse momento foi possível a participação de todos os alunos.

Os dados obtidos com o mapa mental, apontou sobre conhecer e ouvir o outro a partir da sua singularidade. Observou-se que mesmo estando em uma sala de aula a quase um ano de curso, os alunos não se conheciam e não trabalhavam com a comunicação e escuta ativa entre os pares. Visto que, a comunicação e escuta são fatores primordiais e imprescindíveis no cuidado ao paciente.

Ora, através da consciência reflexiva é que se constrói projetos subjetivos, associados com os pares, que possuem projetos semelhantes fornecendo recursos de identificação, ou seja, a construção identitária é a própria atribuição da biografia para si. ${ }^{(13)}$ A partir das histórias que contamos sobre nós, é que podemos saber sobre quem somos.

\section{DISCUSSÃO}

Atualmente o principal desafio para a inclusão das metodologias ativas está relacionado a grade curricular, quanto a falta de tempo e a desarticulação dos conteúdos a serem desenvolvidos; a resistência por parte dos docentes para a implantação da metodologia, pois não querem alterar sua prática de ensino/aprendizagem; e a dificuldade na compreensão em aplicar a metodologia na prática docente, seja por questões sobre a falta de recursos ou por ser mais trabalhoso. ${ }^{(9)}$

De certo, que adultos crescem quando são colocados para fora das zonas de conforto e se percebem obrigados a ampliar os recursos para enfrentar novas situações. Os momentos de crises são geradoras de buscas, seja de conhecimento, seja de relações interpessoais. ${ }^{(13)}$

As dificuldades enfrentadas pelos docentes, para utilização de métodos ativos, ocorrem pelo fato de sua formação ainda ser embasada em aulas expositivas onde os conteúdos são cobrados somente em provas e exercícios. É necessário a mudança 
de postura desse profissional, ele precisa conhecer e utilizar diversos recursos, pensando em sua melhor técnica para aplicar o assunto em sala de aula, através de atividades desafiadoras e contextualizadas. (9) Atualmente, algumas discussões estão sendo levantadas sobre as novas práticas pedagógicas onde as instituições de ensino, estão sendo estimuladas a refazer seu papel social para valorizar a qualidade de sua assistência prestada, inserindo práticas inovadoras no aprendizado. ${ }^{(10)}$

\section{RESULTADOS}

Segundo os dados coletados por meio do mapa mental, os discentes diziam esperar aprender novamente, na integra, as matérias aplicadas no período que se encontravam em aula online e no período anterior a este. Sendo esse um ponto preocupante, pois não dispúnhamos de tempo hábil e os conteúdos apresentados antes do processo de isolamento social, haviam sido validados por meio de avaliações e estágio supervisionado, e mesmo assim foi apontado como "nunca vi isso".

Diante das informações, ficou acordado a implementação da revisão de todo conteúdo. Porém, de forma ativa e participativa, contando com o empenho e participação de ambos os lados, professor e aluno. Sendo requisitado o comprometimento do aluno, para uma leitura previa dos conteúdos, trazendo questionamentos para uma nova roda de conversa e feedback.

Com o proposito, de tornar as aulas dinâmicas e participativa, foi intercalado com apresentações de slides, métodos de aprendizagem como: palavras cruzadas, jogos como quiz, passa ou repassa, storytelling. Para as revisões de farmacologia, aplicava-se modelos de prescrições médicas com nomes fictícios, para que o aluno pudesse interpretar, realizar os cálculos e reconhecer as classes farmacológicas, trazendo situações realísticas, para desenvolver pensamento crítico.

Dentre as atividades realizadas destaco as que mais motivaram os discentes para o momento de aprendizagem sendo elas: storytelling, quiz e passa ou repassa.
Quando se pensa em storytelling, automaticamente associa-se ao ato de contar histórias seja usando os complementos audiodigitais ou não. Mas ele vai além, é uma forma de narrativa, sendo necessário encantar para atingir o objetivo.

\section{Atividades através} dos exercícios de fixação ou por meio de jogos, fortalece o vínculo com o aluno, o momento de descontração e o brincar juntamente com o apreender proporciona 0 trabalho em equipe.

Essa ferramenta foi de suma importância para uma das atividades, onde a história fez sentido, para aquele que ouviu, e partindo desse ponto puderam elaborar uma atividade, correspondente ao contexto narrado.

Isso nos faz compreender que o narrar não cessa ao seu término, ele ressignifica.
A narrativa é ampla e flexível, ao narrar a história o sujeito pode estrutura-la de diferentes formas, o mesmo acontece com a experiência se ela não for narrada certamente não existirá. ${ }^{(14)}$

A partir, do momento que o professor utiliza as ferramentas voltadas para a teoria da andragogia, passa a observar os alunos como sujeitos ativos dentro do processo de aprendizagem, promovendo aproximação entre ambos. Tornando assim, uma aprendizagem envolvente por meio de estratégias inovadoras e adaptadas para o escopo, mantendo o aluno em posição de participante no ensino aprendizagem. ${ }^{(3)}$

Atividades através dos exercícios de fixação ou por meio de jogos, fortalece o vínculo com o aluno, o momento de descontração e o brincar juntamente com o apreender proporciona o trabalho em equipe.

Apesar, de todo o combinado com os discentes e empenho por parte de alguns, não foi possível a interação com os 38 alunos por dois motivos importantes: a não realização da leitura prévia dos conteúdos e o absenteísmo durante a atividade.

Por vezes, as justificativas e solicitações antes das atividades eram, "pode dar um momento agora, para eu estudar", "eu não ouvi que era para ler antecipadamente esse conteúdo". Além disso, muitos faltavam para não participar das atividades e se respaldavam em acompanhar as aulas online. Mas a maior dificuldade encontrada pelo professor, era em relação ao aluno que se encontrava em modo remoto, pois nem sempre dispunha de recursos tecnológicos para participar das atividades, e a plataforma institucional só dispunha do recurso de chat para a interação no momento da prática.

Aos que participaram das atividades presenciais e seguiram as instruções sobre as leituras prévias, observou melhor compreensão do conteúdo, raciocínio crítico e maior desempenho tanto com professor quanto com os colegas.

\section{CONCLUSÃO}

Em vista, do que foi apresentado, as instituições devem fornecer subsídios para 


\section{artigo}

que os docentes possam modificar a sua prática de ensino, sendo capazes de se tornar críticos, reflexivos e questionadores. $\mathrm{O}$ trabalho deve ser coletivo, para se inserir uma pedagogia crítica, com um aprendizado dinâmico, fazendo com que o aluno em sua realidade, possa não causar danos em sua assistência prestada ao paciente. ${ }^{(12)}$

Por outro lado, e este o mais importante reflete sobre o comprometimento dos alunos. Se tratando de uma profissão que visa o cuidado e o aprimoramento por meio de pesquisas, cursos e especializações, se faz necessário conhecimento, habilidades e atitudes. Mas, isso só acontecerá a partir do momento que os futuros profissionais, passarem a ter uma relação humanista e de engajamento com a profissão.

\section{REFERÊNCIAS}

1.Ornell F, Schuch JB, Sordi AO, Kessler FHP. "Pandemic fear" and COVID-19: mental health burden and strategies. Braz. J. Psychiatry [Internet]. 2020 June [cited 2021 Nov 20]; 42(3):232-235. Available from: http://www.scielo.br/scielo.php?script=sci_arttext\&pid=S1516-44462020000300232\&lng=en. Epub Apr 03, 2020. https://doi.org/10.1590/1516-4446-2020-0008.

2. Costa R, Lino MM, Souza AlJ, Lorenzini E, Fernandes GCM, Brehmer LCF et al. Ensino de enfermagem em tempos de covid-19: como se reinventar nesse contexto? Texto contexto enferm. [Internet]. 2020 [citado 2020 Nov 22]; 29: e20200202.

Disponivel em: http://www.scielo.br/scielo.php?script=sci_arttext\&pid=S0104-07072020000100102\&Ing=pt. Epub 08-Jun-2020. https://doi.org/10.1590/1980-265xtce-2020-0002-0002.

3. Draganov PB, Friedländer MR, Sanna MC. Andragogia na saúde: estudo bibliométrico. Esc. Anna Nery [Internet]. 2011 Mar [cited 2019 Jan 03]; 15(1): 149- 156.Available from:

http://www.scielo.br/scielo.php?script=sci_arttext\&pid=S1414-8145201100010002 1\&Ing=en. http://dx.doi. org/10.1590/S1414-81452011000100021.

4. Passeggi, MC. Narrativas da experiência na pesquisa-formação: do sujeito epistêmico ao sujeito biográfico. Rot. [Internet]. $23^{\circ}$ de março de 2016 [citado 23 de novembro de 2020];41(1):67-86. Disponivel em:

https://portalperiodicos.unoesc.edu.br/roteiro/article/ view/9267

5. Lima VV. Espiral construtivista: uma metodologia ativa de ensino-aprendizagem. Interface (Botucatu) [Internet]. 2017 June [cited 2019 Jan 02]; 21(61): 421-434. Available from: http://www.scielo.br/scielo.php?script=sci_arttext\&pid=S14143283201700020042 1\&lng=en. Epub Oct 27,2016 .

6. Mitre SM, Siqueira-Batista R, Girardi-de-Mendonça JM, Morais-Pinto NM, Meirelles CAB, Pinto-Porto $C$ et al. Metodologias ativas de ensino-aprendizagem na formação profissional em saúde: debates atuais. Ciênc. saúde coletiva [Internet]. 2008 Dec [cited 2019 Jan 03]; 13(Suppl 2): 2133-2144. Available from:

http://www.scielo.br/scielo.php?script=sci_arttext\&pid=S141381232008000900018\&lng=en.

7. Samia MA, Matsubara FH, Costa PM. Mensuração da motivação dos alunos em uma sala de aula ativa com oito horas de duração em um curso semipresencial da área de saúde. In: Jornada Virtual ABED de Educação a Distância: relato de experiencia inovadora (EI); 2017 Jun 5-21; Anais. Curitiba (PR).:ABED;2017.
8. Thofehrn MB, Leopardi MT, Amestoy SC. Construtivismo: experiência metodológica em pesquisa na enfermagem. Acta paul. enferm. [Internet]. 2008. [cited 2019 Jan 03];21(2):312-316. Available from:

http://www.scielo.br/scielo.php?script=sci_arttext\&pid=S01032100200800020001 3\&lng=en.

9. Mesquita SKC, Meneses, RMV, Ramos DKR. Metodologias ativas de ensino/aprendizagem: dificuldades de docentes de um curso de enfermagem. Trab. educ. saúde. [online]. 2016, April [cited 2019 Jan 02]; 14(2), 473-486. Available from:

http://www.scielo.br/scielo.php?script=sci_arttext\&pid=S198177462016000200473\&lng=en.

10. Sobral FR, Campos CJG. Utilização de metodologia ativa no ensino e assistência de enfermagem na produção nacional: revisão integrativa. Rev. esc. enferm. USP [Internet]. 2012 Feb [cited 2019 Jan 04]; 46(1): 208-218. Available from:

http://www.scielo.br/scielo.php?script=sci_arttext\&pid=S00806234201200010002 8\&Ing=en.

11. Waterkemper R, Prado ML. Estratégias de ensino-aprendizagem em cursos de graduação em Enfermagem. av. enferm. [Internet]. 2011 Dec [cited 2019 Jan 04]; 29(2): 234-246. Available from:

http://www.scielo.org.co/scielo.php?script=sci_arttext\&pid=S01214500201100020 0003\&lng=en.

12. Carraro TE, Prado ML, da Silva DGV, Radünz V, Kempfer SS, Sebold LF. Socialização como processo dinâmico de aprendizagem na enfermagem. Uma proposta na metodologia ativa. Invest Educ Enferm. 2011July [cited 2019 Jan 04];29(2): 248-254. Available from:

http://www.scielo.org.co/scielo.php?script=sci_arttext\&pid=S012053072011000200010\&Ing=en\&tlng=pt.

13. Furlanetto EC. Os processos de construção identitária docente: a dimensão criativa e formadora das crises. Formação Docente - Revista Brasileira de Pesquisa sobre Formação de Professores, v. 4, n. 7, p. 115-125, 21 jun. 2018. [cited 2020 Mai 25]. Available from: https://revformacaodocente.com.br/index.php/ rbpfp/article/view/66/56

14. Passeggi MC. Enfoques narrativos em la investigación educativa brasileña. Paradigma [Internet]. 30 de junio de 2020 [citado 02 de enero de 2021]; 00:57-9. Disponible en:

http://revistaparadigma.online/ojs/index.php/paradigma/article/view/929 